\title{
COLOR DUPLEX VERSUS CT ANGIOGRAPHY IN ASSESSMENT OF INFRA POPLITEAL ARTERIAL CIRCULATION IN DIABETIC PATIENTS: A COMPARATIVE STUDY
}

\author{
By
Yahya Ahmed Hassan Mohammed, Ahmed Aboul Fotouh and Mohamed El-Feshawy \\ Department of Radiodiagnosis, Faculty of Medicine, Al-Azhar University \\ Corresponding author: Yahya Ahmed Hassan Mohammed, \\ E-mail: yahya_hassan2000@gmail.com
}

\begin{abstract}
Background: Peripheral vascular disease is narrowing or occlusion of arteries mostly due to atherosclerosis which is very common in patients with diabetes mellitus (DM).

Objective: To compare lower limb arterial diseases using Color duplex and multi-detector CT angiography (MDCTA) and to find the better non-invasive modality of choice.

Patients and Methods: Thirty diabetic patients of lower limb peripheral arterial disease underwent Color duplex and multi-detector CT angiography (MDCTA). Infra popliteal arterial system, divided into anatomic segments and luminal narrowing, were compared using color duplex and axial images of arterial phase of CT angiography. Using statistical methods, sensitivity, specificity and accuracy of color duplex and CT angiography were determined.

Results: One hundred and fifty six arterial segments were studied with CT angiography and color duplex. Out of the total 156 vessel segments, color duplex was able to detect 140 (89.7\%) diseased segments, while MDCTA which was able to detect 114 (73\%) diseased segments. Color duplex was able to pick up grade 1 lesions better than MDCT angiography with sensitivity $91.6 \%$. Grade 2 and grade 3 were better picked up by MDCT angiography with color duplex sensitivity of $80 \%$ and $76 \%$ for grade 2 and grade 3 respectively. The two modalities showed comparable results for grade 4 lesions with sensitivity of $85.7 \%$. Significant statistical agreement existed between color duplex and CT angiography with moderate total agreement (Weighted kappa estimation $(\mathrm{Kw})=0.64)$ for grade 1 lesions, fair total agreement $(\mathrm{Kw}=0.39)$ for grade 2 lesions, good total agreement $(\mathrm{Kw}=0.75)$ for grade 3 and very good agreement $(\mathrm{Kw}=0.88)$ for grade 4 lesions.

Conclusion: Color duplex is a safe, inexpensive, non-invasive, easily available diagnostic tool with high diagnostic accuracy in the investigation of peripheral arterial disease PAD among patients with diabetes mellitus DM. Color duplex is better than CT angiography in the diagnosis of Grade 1 and 2 lesions. CT angiography is more accurate in assessing grade 3 and grade 4 stenosis. Color duplex remains the only available diagnostic tool in diabetic patients with contraindications for contrast media administration.
\end{abstract}

Keywords: MDCT Angiography, Color Doppler Ultrasonography, Peripheral Arterial Disease.

\section{INTRODUCTION}

Peripheral arterial disease (PAD) is a common manifestation of atherosclerosis and is defined as any pathologic process causing obstruction to blood flow in the arteries, exclusive of the coronary and cerebral vascular beds. PAD affects a 
large slice of the adult population. Less than $20 \%$ of patients with PAD have typical symptoms of intermittent claudication, whereas another third have atypical exertional leg symptoms (Algazzar et al., 2014).

The history and physical examination usually provide sufficient information to determine the presence of significant arterial occlusive disease. Hemodynamic vascular tests are subsequently performed to confirm the clinical diagnosis and to further define the level and extent of the disease (El-Saied et al., 2015).

Peripheral artery disease (PAD) is a spectrum of occlusive arterial syndromes that can range from asymptomatic obstructive disease through occlusive disease requiring amputation. This spectrum becomes more progressive and symptomatic as the disease causes an imbalance of distal perfusion pressure to the tissue and metabolic demands within that tissue (Gulati et al., 2017).

On the latter end of this spectrum, chronic critical limb ischemia (CLI) has a prevalence that is more difficult to define and is quite variable in the published literature. Unlike asymptomatic PAD or exertional claudication, CLI occurs with inadequate perfusion at rest (Gulati et al., 2017).

Like most of the terminology of peripheral vascular disease, the definitions of CLI have evolved over the years, with first an increasing need to classify the entire continuum of PAD, the need to further classify those undergoing surgical procedures, and then to include more objective measures as well as the clinical presentation (Dieter et al., 2016).
Conventional angiography and digital subtraction angiography were the only angiographic techniques used in peripheral vascular disease and are considered to be a gold standard investigation. However, the complications and patient discomfort associated with these techniques have prompted the need of less invasive means of assessing the peripheral arterial system (Parikh et al., 2017).

Color duplex has shown to be one such widely available, noninvasive modality which involves no radiation and provides an early diagnosis. On the other hand, multi detector CT (MDCT) angiography, is minimally invasive, with fairly accurate results.

The aim of the present study was to compare the efficacy of Color duplex and MDCT angiography as none or minimally invasive techniques for investigating the lower limb arterial disease.

\section{PATIENTS AND METHODS}

The presented study has been conducted on 30 selective diabetic patients with PAD admitted in El Sahel Teaching Hospital during a period from April 2018 to May 2019.

Color duplex was done using (GE Logiq P5 machine) for one limb or both according to patient complaint and to detect lesion distribution (proximal, distal or multi-segmental). Peak systolic velocity (PSV), waveform were evaluated to detect single or multiple small or long stenosis or occlusion and to know the degree of stenosis.

A scout image (tube voltage, $120 \mathrm{kV}$; tube current, $50 \mathrm{mAs}$ ) was followed by 
plan to include infrarenal aorta in lower limbs. The mean coverage was $1140 \mathrm{~mm}$ (range: $1032-1245 \mathrm{~mm}$ ). 70 to $100 \mathrm{ml}$ (mean $80 \mathrm{ml}$ ) of nonionic iodinated contrast medium (Omnipaque 370mg iodine per $\mathrm{mL}$ ) administered using 18 or $20 \mathrm{G}$ venous catheter, placed in antecubital fossa. The amount of contrast decided to establish bolus duration that was equivalent to scanning time. The contrast administered using automated injector at 4 $\mathrm{mL} / \mathrm{sec}$ flow rate and followed by $30-\mathrm{mL}$ saline flush. Using bolus tracking technique, a region of interest was set in aorta. Repetitive low-dose monitoring (120 kV, $10 \mathrm{mAs}$ with one second interscan delay) performed two seconds after contrast injection. After reaching contrast threshold of $120 \mathrm{HU}$, scanning $(120 \mathrm{kV}$ and $250 \mathrm{~mA}$ adults; $150 \mathrm{~mA}$ for children) initiated automatically. Data acquisition performed in cranio-caudal direction with slice thickness of $0.75 \mathrm{~mm}$, table feed of $18 \mathrm{~mm}$ per rotation and $0.33 \mathrm{~s}$ gantry rotation time.

Axial sections were reconstructed with a thickness of $1 \mathrm{~mm}$ and no interslice gap, which resulted in mean of 1500 (range 1400-1700) axial images. The mean total scan time, which was defined as the time from patient entry into the $\mathrm{CT}$ suite until scanning was finished, was 6 minutes. No specific complications or technical difficulty encountered. All CTA images transferred to a workstation for 3D reconstructions, maximum intensity (MIP) and volume renderings (VRT) images. Axial and reconstructed images were analyzed and graded.

The infrapopliteal lower limb arterial system was divided into 4 anatomical regions: including tibio-peroneal trunk, anterior and posterior tibial artery and dorsalis pedis artery. Each and every anatomical segment of the arterial tree was assigned a grade for the disease extent as visualized using a five point scale: $0=$ Normal, $1=$ Mild stenosis $(1-49 \%$ diameter reduction), $2=$ Moderate stenosis (50-74\% diameter reduction), 3=Severe stenosis (75-99\% Diameter reduction), 4=Occlusion. The findings of the modalities were then compared.

\section{Statistical analysis:}

All data were collected, tabulated and statistically analyzed using SPSS 22.0 for windows (SPSS Inc., Chicago, IL, USA). All statistical comparisons were three tailed with significance Level of P-value $\leq$ 0.05 data were presented as frequency and percentage. 


\section{RESULTS}

The total number of arterial segments assessed by Duplex ultrasonography was 156 segments. MDCT angiography however being done for both limbs, comparative study focused on the limb of interest previously underwent Duplex ultrasonography. Of the 21 patients who underwent unilateral duplex ultrasonography examination 12 of them were right sided examined and 9 were left sided examined (Table 1).

Table (1): Distribution of patients according to number of examined extremities

\begin{tabular}{|c|c|c|c|c|}
\hline \multirow{2}{*}{ Measurement } & \multicolumn{2}{c|}{ Color duplex } & \multicolumn{2}{c|}{ MDCT angiography } \\
\cline { 2 - 5 } & Number & Percentage & Number & Percentage \\
\hline Unilateral (right or left) & 21 & $70 \%$ & 6 & $20 \%$ \\
\hline Bilateral (both limbs) & 9 & $30 \%$ & 24 & $80 \%$ \\
\hline Total & 30 & $100 \%$ & 30 & $100 \%$ \\
\hline
\end{tabular}

\section{Age \& Sex Distribution}

In our study, most of patients were between 50 \& 60 years. Most of cases were among males accounting for $80 \%$ of total number of cases (Table 2).

Table (2): Age distribution

\begin{tabular}{|c|c|c|c|c|c|c|}
\hline \multirow{2}{*}{ Gender } & \multicolumn{2}{|c|}{ Males } & \multicolumn{2}{c|}{ Females } & \multicolumn{2}{c|}{ Total } \\
\cline { 2 - 7 } Age & Number & Percentage & Number & Percentage & Number & Percentage \\
\hline $40-49$ & 7 & $23.3 \%$ & 0 & $0 \%$ & 7 & $23.3 \%$ \\
\hline $50-59$ & 15 & $50 \%$ & 4 & $13.3 \%$ & 19 & $63.3 \%$ \\
\hline $60-70$ & 2 & $6.7 \%$ & 2 & $6.7 \%$ & 4 & $13.3 \%$ \\
\hline Total & 24 & $80 \%$ & 6 & $20 \%$ & 30 & $100 \%$ \\
\hline
\end{tabular}

The present study revealed that out of the total 156 vessel segments, color duplex is able to detect 140 (89.7\%) positive cases, in comparison to the MDCTA which was able to detect 114 (73 $\%)$ positive cases.

Color duplex was able to pick up grade 1 lesions better than MDCT angiography with sensitivity $91.6 \%$ and specificity 93\%. Grade $2 \&$ grade 3 were better picked up by MDCT angiography with color duplex sensitivity of $80 \%$ \& $76 \%$ for grade $2 \&$ grade 3 respectively. The two modalities show comparable results for grade 4 lesions with Color duplex sensitivity $85.7 \%$ and specificity $99.2 \%$.

Color duplex has more overall detection rate than MDCT angiography regarding picking up and assessment of grade $1 \&$ grade 2 lesions $(0.9 \%$ \& $42 \%$ with color duplex compared to $0.6 \% \&$ $23.5 \%$ with MDCT angiography). Color duplex can detect early and preclinical atherosclerotic changes within different arterial segments lumen. We noticed that mild mural thickening which was unseen by MDCT angiography could be detected by $\mathrm{B}$ mode.

The study revealed also moderate total agreement between the two modalities (Weighted kappa estimation $(\mathrm{Kw})=0.64)$ for grade 1 lesions between the two diagnostic modalities, fair total agreement $(\mathrm{Kw}=0.39)$ for grade 2 lesions and good total agreement $(\mathrm{Kw}=0.75)$ for grade 3 and very good agreement $(\mathrm{Kw}=0.88)$ for grade 4 lesions. 

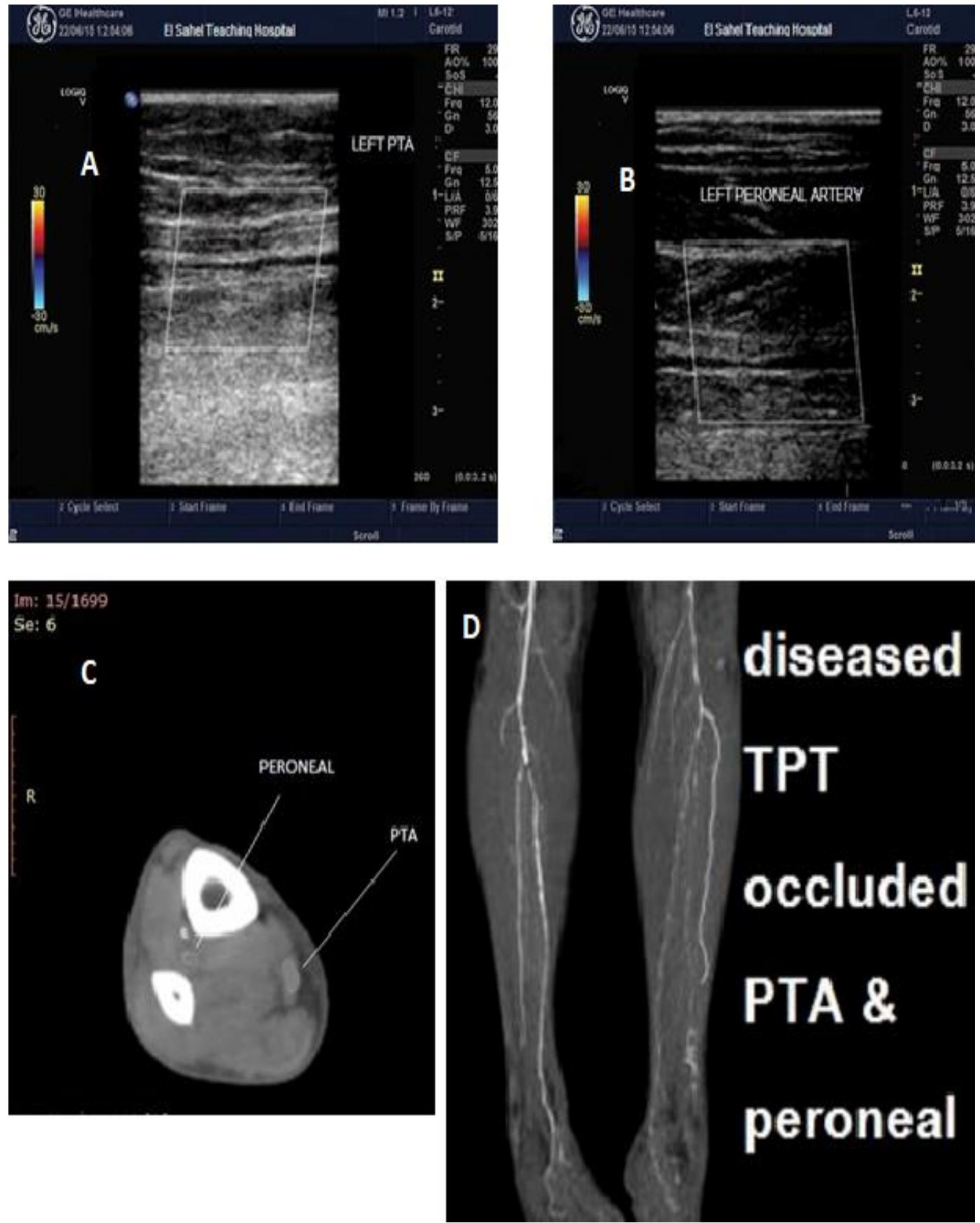

Figure (1): A\& B showed Doppler findings with markedly diseased TPT\& Occluded PTA\& peroneal artery, C\& D images showed corresponding CT angiographic findings with Attenuated TPT and Occluded PTA and peroneal artery. 

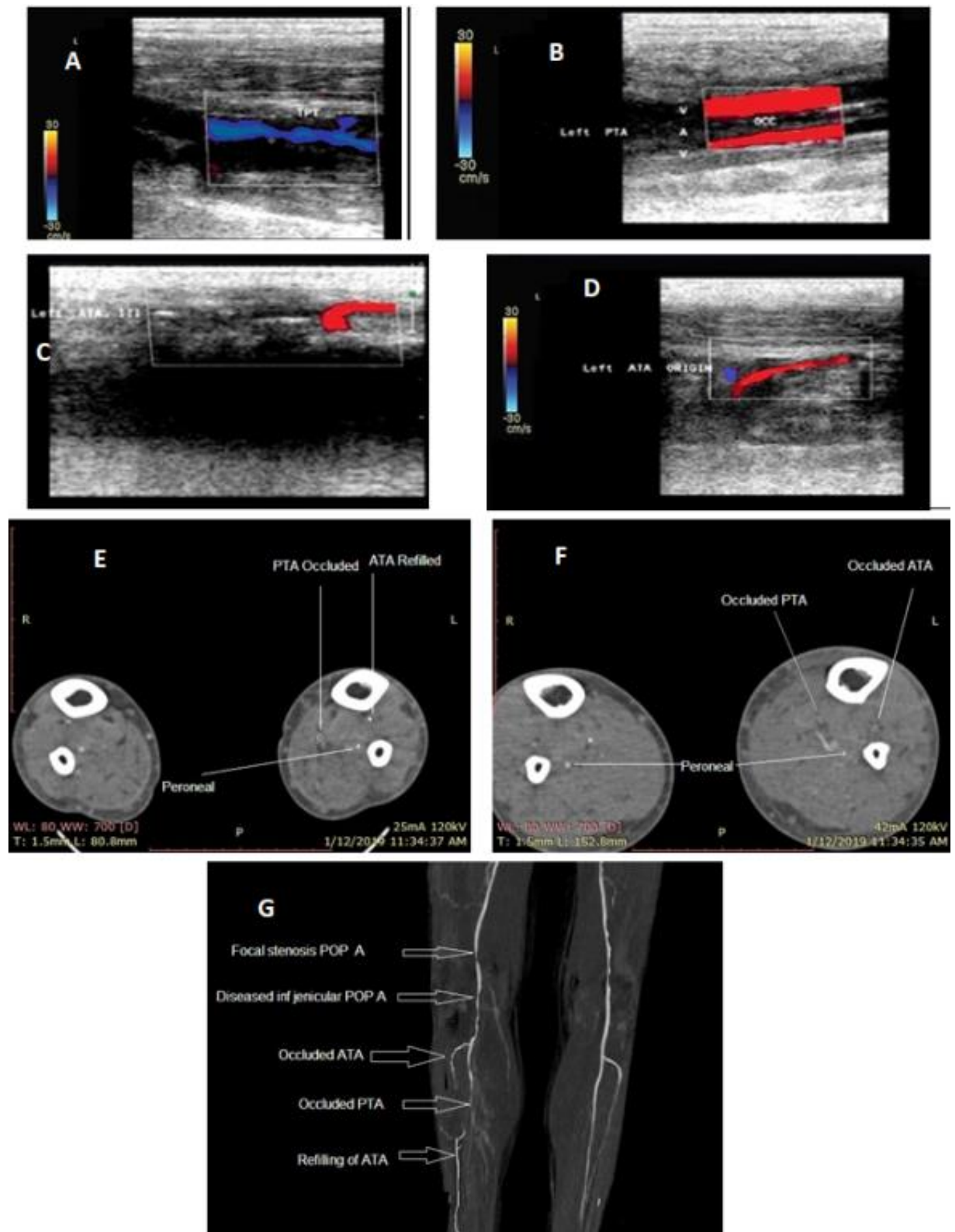

Figure (2): A, B, C\& D images showed Doppler findings with markedly diseased TPT with multiple tight focal stenosis, occluded ATA shortly after its origin with markedly diseased proximal segment and distal refilling using lower PRF settings and Occluded PTA\& markedly attenuated distal peroneal artery, E, F\& G images showed corresponding CT angiographic findings with multiple focal stenoses of TPT, well-formed collaterals, totally occluded PTA and ATA shortly after its origin with distal refilling and faintly opacified left DPA. 

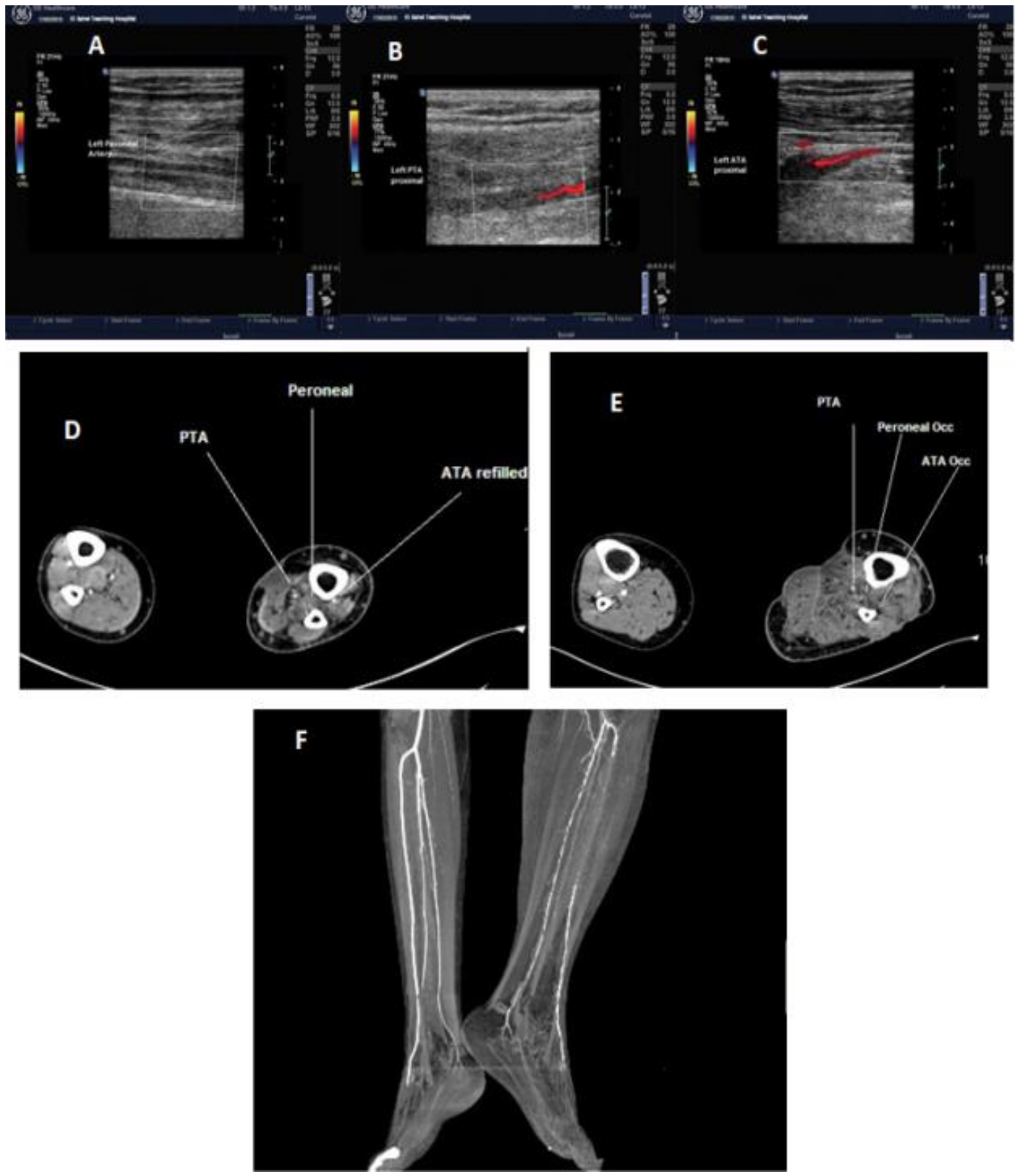

Figure (3): A 51 years old diabetic hyperlipidemic male patient, presented with moderate rest pain of diabetic right foot. $A, B \& C$ images showed Doppler findings with non-delineated TPT, occluded left ATA shortly after its origin with thread-like distal refilling, occluded lefty peroneal artery and markedly diseased left PTA with multiple segmental and focal occlusions, D, E\& F images showed corresponding $\mathrm{CT}$ angiographic findings with direct trifurcation of left popliteal artery into three branches (ATA, PTA\& peroneal branches) with no TPT (anatomical variant), occluded ATA shortly after its origin with thread-like distal refilling, occluded peroneal artery\& markedly diseased PTA. 
Color duplex was able to pick up flow in some infrapopliteal vessels which were not opacified with contrast. In three patients with proximal significant stenosis, there was no opacification in the infrapopliteal vessels with the contrast, but color duplex was able to pick up monophasic flow. This could be because of different rates of crural vessel opacification, or inadequate opacification distal to an occlusion in CT angiography. This implies that when color duplex is used in conjunction with CT angiography,

\section{DISCUSSION}

In our study, color duplex is able to detect $(89.7 \%)$ positive cases, in comparison to the MDCTA which was able to detect $(73 \%)$ positive cases. Color duplex detected no abnormality (Grade 0 stenosis) in $(23 \%),(10.2 \%),(2.5 \%)$ and $(2.5 \%)$ cases in the tibio-peroneal trunk, anterior tibial, posterior tibial and dorsalis pedis segments respectively. MDCT angiography demonstrated no abnormality (Grade 0 stenosis) in (43\%), (30.7\%), $(23 \%)$ and $(10.2 \%)$ cases in the tibioperoneal, anterior tibial, posterior tibial and dorsalis pedis arterial segments respectively.

Netam et al. (2015) included both suprapopliteal and infrapopliteal arterial tree noted that the CDUS was able to detect more number of the stenotic arterial segments in the both supra-popliteal and infra-popliteal region than CTA. In infrapopliteal segment $72(36 \%)$ segments were picked by CDUS in comparison to the $65(32.5 \%)$ segments by CTA. Anu Maithrayee et al. (2015) showed that the sensitivity of Doppler in evaluating aortoiliac segments, femoropopliteal segments and infrapopliteal segments the false positive occlusions of CT angiography could be minimized.

Color duplex has more overall detection rate than MDCT angiography regarding picking up and assessment of grade $1 \&$ grade 2 lesions $(0.9 \%$ \& $42 \%$ with color duplex compared to $0.6 \%$ \& $23.5 \%$ with MDCT angiography). Color duplex can detect early and preclinical atherosclerotic changes within different arterial segments lumen. We noticed that mild mural thickening which was unseen by MDCT angiography could be detected by $\mathrm{B}$ mode.

were $87.5 \%, 100 \%$ and $75.32 \%$ respectively and specificity in evaluating aortoiliac segments, femoropopliteal segments and infrapopliteal segments were $100 \%, \quad 96.01 \%$ and $83.06 \%$ respectively if CT angiography was taken as gold standard. Ramaswami et al. (2015) showed that duplex scanning is a useful screening tool and may be effectively used to diagnose the arterial disease in nearly $80 \%$ of patients. Elsaied et al. (2015) showed that duplex scanning is a useful screening tool and may be effectively used to diagnose the arterial disease in $100 \%$ of patients.

We found that the dorsalis pedis artery followed by posterior tibial artery were the most frequently segments to be affected with color duplex detection rate of $97.4 \%$ for both segments lesions and MDCT angiography detection rate of 89.7 $\%$ \& $76.9 \%$ respectively.

Das et al. (2015) stated that the most common artery with luminal narrowing in our study was dorsalis pedis followed by anterior \& posterior tibial arteries. Shaheen et al. (2010) had evaluated one hundred clinically and biochemically proven cases of diabetes and found out 
that dorsalis pedis was the most commonly affected site on peripheral vascular sonography with $24 \%$ patients being affected.

Both color duplex and MDCT angiography in our study show comparable results in detection rate of luminal narrowing (Grades 1, 2\& 3) in tibio-peroneal and anterior tibial segments $(69.2 \% \& 76.9 \%)$ in color duplex and $46.1 \%$ \& $61.5 \%$ in the same segments for MDCT angiography). However, color duplex shows much higher sensitivity in detection of luminal narrowing in posterior tibial and dorsalis pedis arteries (84.6\% \& 82\%) in color duplex compared to $61.5 \% \& 69.2 \%$ in the same segments for MDCT angiography).

Nagar et al. (2016) revealed overestimation of degree of stenosis on Doppler USG by one grade in 87 segment. 18 segments were overestimated as two grades, 57 segments by 3 grade and 39 segments by four grades overestimation. They found that Doppler USG over estimated grade of stenosis in distal tibial vessels in correlation with CTA. They found that It is difficult to assess tiny lesions in multi-segmental peripheral occlusive arterial disease. Another reason was lack of flow in distal arteries in patients with proximal occlusive lesions. Chidambaram et al. (2016) also concluded that Doppler USG overestimated the degree of stenosis by one grade in 47 segments ( 25 of which were considered normal at CT angiography but were diagnosed as mildly stenotic at Doppler USG), by two grades in 11 segments, by three grades in 30 segments and by four grades in 22 segments.
Color duplex was able to pick up grade 1 lesions better than MDCT angiography with sensitivity $91.6 \%$ and specificity 93\%. Grade 2 \& grade 3 were better picked up by MDCT angiography with color duplex sensitivity of $80 \%$ \& $76 \%$ for grade $2 \&$ grade 3 respectively. The two modalities show comparable results for grade 4 lesions with Color duplex sensitivity $85.7 \%$ and specificity $99.2 \%$.

Leoniuk et al. (2014) proved that even preclinical changes in foot arteries can be detected by Duplex ultrasound based up on overall diameter of arteries in diabetic patients and vessel wall thickening as an early symptom of diabetes-related changes .In addition in their study, $\mathrm{HbA} 1 \mathrm{c}$ level in diabetic patients is positively correlated with the resistance index (RI) however Doppler flow parameters assessed in patients at the early stage of diabetes are not significantly different from those observed in healthy individuals. Shirol et al. (2015) found that $80 \%$ of the cases of wall thickening were seen on color Doppler whereas CT showed wall thickening only in $68.33 \%$.

\section{CONCLUSION}

Color duplex is considered a very useful noninvasive diagnostic tool for the assessment of the vascular system without resorting to invasive radiographic studies as CTA, it determine artery wall thickness, degree of flow turbulence, anatomic locations, hemodynamic, lesion morphology and amounts of stenosis or obstruction. Color duplex can be used solely in cases with contraindications to MDCTA like patients with diabetic nephropathy who cannot receive iodinated contrast media with high diagnostic 
accuracy and comparable results with MDCTA.

\section{REFERENCES}

1. Algazzar MA, Elzawawi MS, Alhawary KE and Mousa WA. (2014): Role of multidetector computed tomography angiography in the evaluation of lower limb ischemia. Int $\mathbf{J}$ Med Imaging, 2(5):125-30.

2. American Diabetes Association (2018): Peripheral arterial disease in people with diabetes. Diabetes Care, 12: 3333-3341.

3. Anu Maithrayee K (2015): Lower Limb Arteries Assessed with Doppler AngiographyA Prospective Comparative Study with Multi Detector CT Angiography (Doctoral dissertation, Madras Medical College, Chennai).

4. Elsaied FM, Sherief HM and Abdelwahab M (2015): Reliability and dependency of color coded duplex ultrasonography in comparison to multidetector computed tomography angiography in diagnosis and selection of treatment strategy of peripheral arterial disease of the lower limb. Al-Azhar Assiut Medical Journal, 13(4): 116-119.

5. Das G, AKr G, Aggarwal A (2015): Assessment of lower limb arteries by Doppler sonography in diabetic patients. Int $\mathrm{J}$ Res Health Sci. 2015; 3:18-23.

6. Chidambaram PK, Swaminathan RK, Ganesan P, Mayavan M (2016): Segmental comparison of peripheral arteries by Doppler ultrasound and CT angiography. Journal of clinical and diagnostic research: JCDR. 2016 Feb; 10(2):TC12.

7. Dieter RS, Dieter RA, Dieter RA and Nanjundappa A (2016): Critical limb ischemia: acute and chronic. Pbl. Springer, PP. 315-322.

8. Gulati A, Garcia L and Acharji S. (2017): Epidemiology of chronic critical limb ischemia. In Critical Limb Ischemia. Pbl. Springer, Cham, Pp. 9-14.

9. Leoniuk J, Lukasiewicz A, Szorc M, Sackiewicz I, Janica J, Lebkowska U (2014): Doppler ultrasound detection of preclinical changes in foot arteries in early stage of type 2 diabetes. Polish journal of radiology. 2014; 79:283.

10. Nagar A, Sakhi P, Singh S. (2016): Over and under estimation of arterial stenosis grade by Doppler and comparison with CT angiography.

11. Netam SS, Singh R, Kumar S, Singhal A and Jain V. (2015): CT angiography evaluation of peripheral vascular disease and comparison with color doppler ultrasound. Journal of Evolution of Medical and Dental Sciences, 4(83):14504-14.

12. Parikh $C$, Brahmbhatt $P$ and Raychaudhuri C. (2017): Efficacy of color doppler imaging over CT angiography in peripheral arterial disease. Journal of Integrated Health Sciences, 5(2):45-49.

13. Ramaswami G, Al-Kutoubi A, Nicolaides AN, Dhanjil S, Griffin M, Belcaro G, Coen LD (2015): The role of duplex scanning in the diagnosis of lower limb arterial disease. Annals of vascular surgery. 2015 Sep 1; 13(5):494500.

14. Shaheen R, Sohail S (2010): A doppler-based evaluation of peripheral lower limb arterial insufficiency in diabetes mellitus. J Coll Physicians Surg Pak. 2010 Jan 1; 20(1):22.

15. Shirol RJ, Shetty A and Chethan TK. (2015): Role of MDCT in evaluation of peripheral vascular disease of the lower limb arteries and comparison with colour Doppler. J Evol Med Dent Sci., 4(54): 9336-47. 


\section{المقارنة بين إستخدام اللدوبلكس الملوز و بين التصوير بالأشعة المقطعية

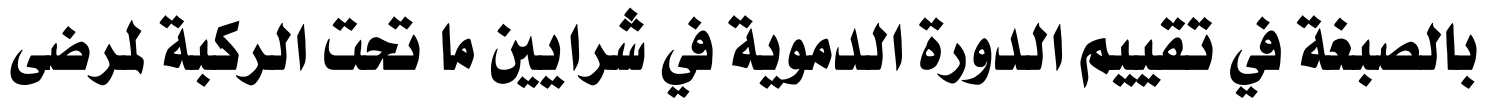

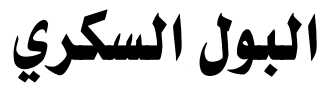

يحيى أحمد حسن محمد, أحمد أبو الفتوح, محمد الفيشاوي

قسم الأثثعة التثخيصية ـ كلية الطب, جامعة الأزهر

E-mail: yahya_hassan2000@gmail.com

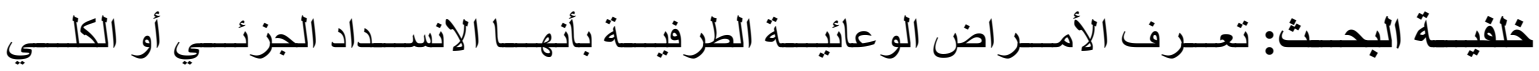

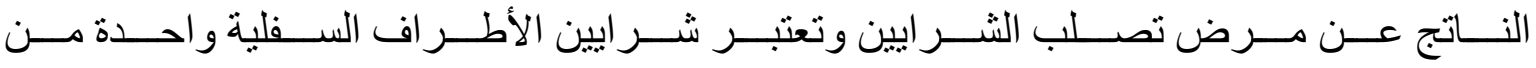

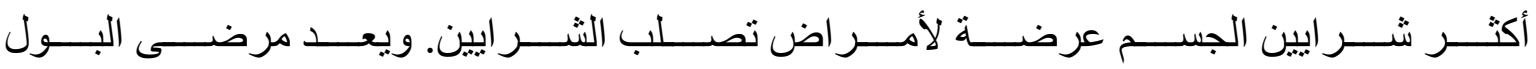
السكري هم الاكثر عرضة لأمر اض تصلب الثر ايين.

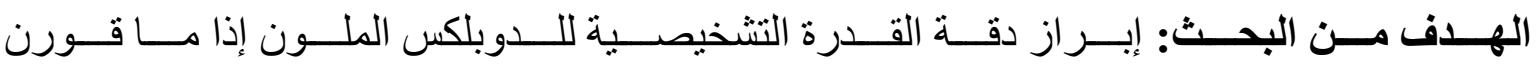

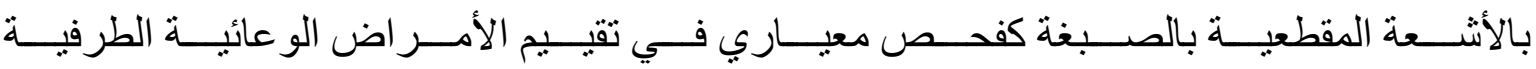

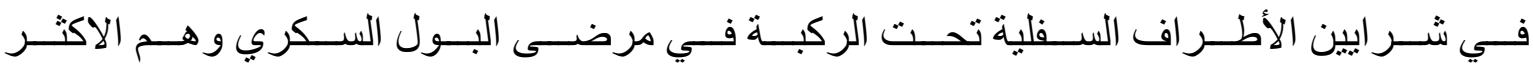

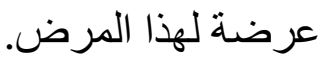

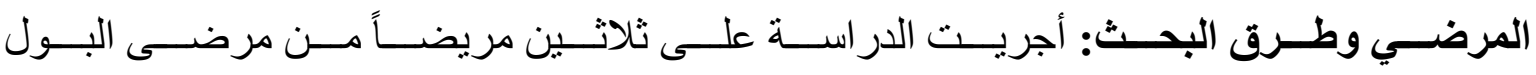

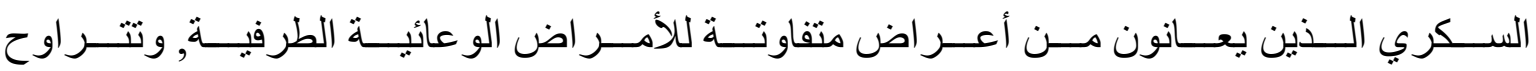

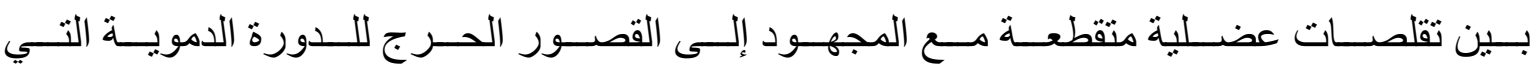
قد تقسبب في غرغرينا الأطر اف.

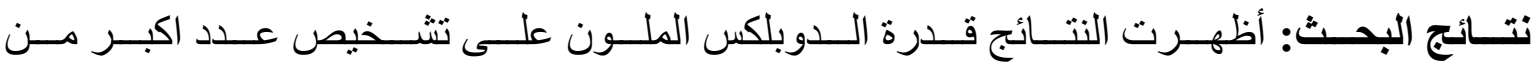

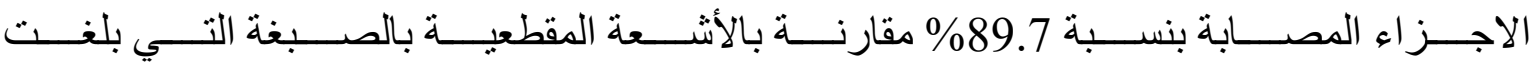

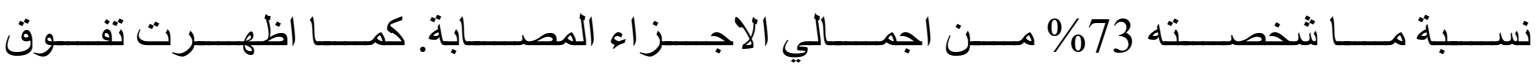

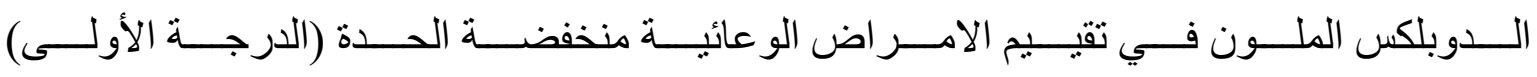

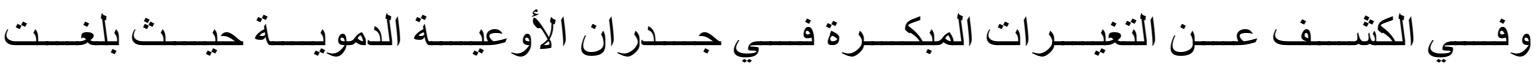

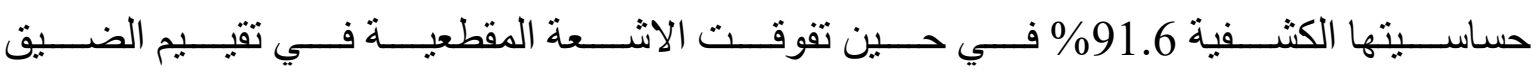

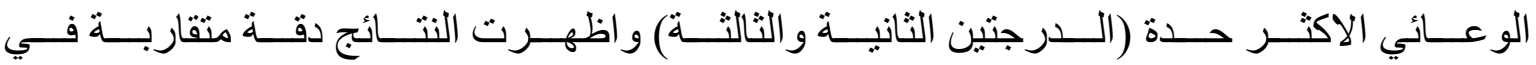

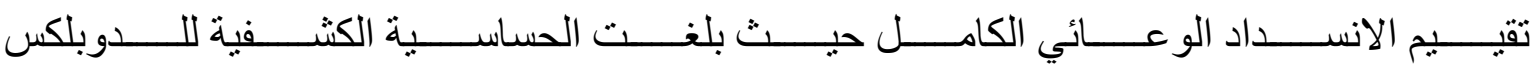




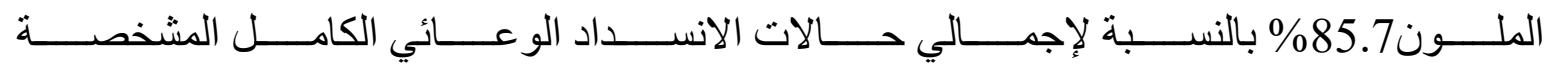
بالأشعة المقطعية بالصبغة.

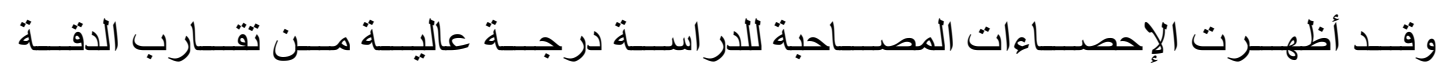

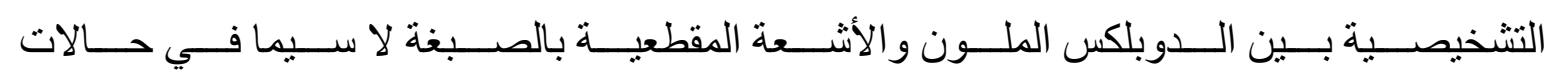

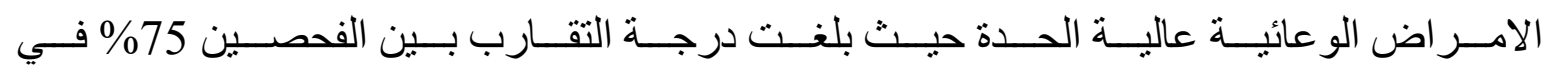

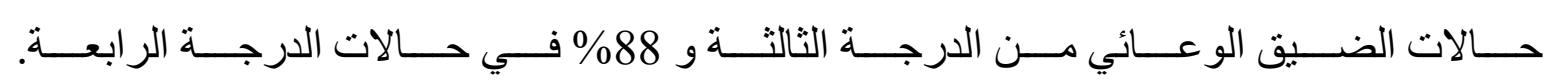

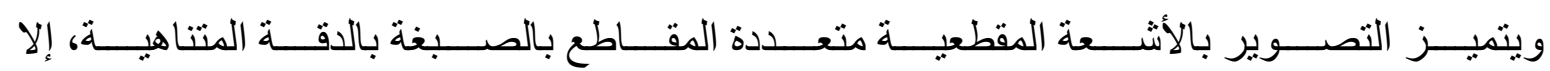

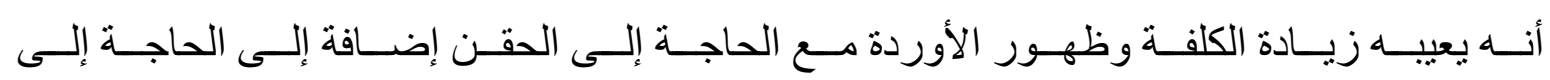
حقن مو اد التباين اليودية المسممة للكلى و التعرض للأشعة المؤينة.

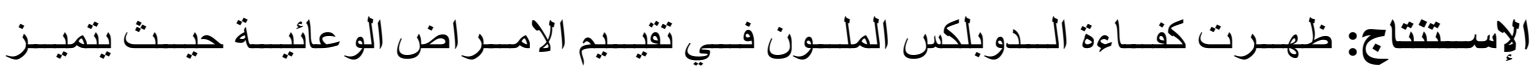

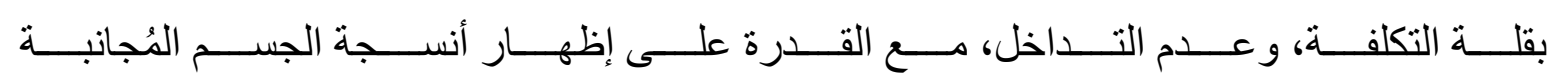
للثر ايين، كما إنها أكثر ملائمة للفحوصات الدورية.

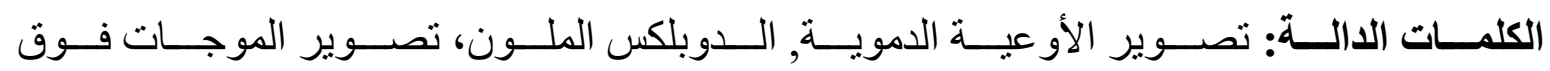
الصوتية بالدوبلر الملون، مرض الثرايين المحيطية. 